\title{
Understanding the role of individual learner in adaptive and personalized e-learning system
}

\author{
Alva Hendi Muhammad, Dhani Ariatmanto \\ Magister of Informatics Engineering, Universitas Amikom Yogyakarta, Indonesia
}

\begin{tabular}{l}
\hline \hline Article Info \\
\hline Article history: \\
Received Jul 22, 2021 \\
Revised Sep 24, 2021 \\
Accepted Oct 27, 2021
\end{tabular}

\section{Keywords:}

Adaptation and personalization Adaptive learning system Dynamic learning Learner model attributes Student modeling

\begin{abstract}
Dynamic learning environment has emerged as a powerful platform in a modern e-learning system. The learning situation that constantly changing has forced the learning platform to adapt and personalize its learning resources for students. Evidence suggested that adaptation and personalization of e-learning systems (APLS) can be achieved by utilizing learner modeling, domain modeling, and instructional modeling. In the literature of APLS, questions have been raised about the role of individual characteristics that are relevant for adaptation. With several options, a new problem has been raised where the attributes of students in APLS often overlap and are not related between studies. Therefore, this study proposed a list of learner model attributes in dynamic learning to support adaptation and personalization. The study was conducted by exploring concepts from the literature selected based on the best criteria. Then, we described the results of important concepts in student modeling and provided definitions and examples of data values that researchers have used. Besides, we also discussed the implementation of the selected learner model in providing adaptation in dynamic learning.
\end{abstract}

This is an open access article under the CC BY-SA license.

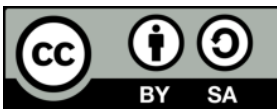

\section{Corresponding Author:}

Alva Hendi Muhammad

Magister of Informatics Engineering

Universitas Amikom Yogyakarta

Jl. Ring Road Utara, Condongcatur, Depok, Sleman, 55281 Indonesia

Email: alva@amikom.ac.id

\section{INTRODUCTION}

The coronavirus disease-19 (covid-19) pandemic has forced traditional classroom learning to be replaced by online learning thru e-learning platforms. E-learning has been the subject of much systematic investigation, and its form has a long history of change. The first generation of e-learning (1960-1980) introduced by Patrick Suppes and Donald Bitzer was in the form of computer instruction, known as computer assisted instruction (CAI) or computer assisted learning (CAL). The second generation of e-learning (19902005) was heavily influenced by personal computer (PCs), multimedia compact disc, read-only-memory (CD-ROMs), and the internet. This generation emerged web-based e-learning. The third generation of e-learning (2006-2015) was influenced by smartphones and online video services. This form of e-learning was known as a mobile learning and ubiquitous learning system. To date, e-learning has entered the fourth generation, which is characterized by the open and massive number of students through massive open online courses (MOOC). The use of e-learning that continues to expand has been the common learning solution during the pandemic.

Existing research recognizes that among varied forms of e-learning that exist today, the same characteristic lies behind the e-learning system that was generically designed to facilitate all user characters (one-size-fits-all). Criticism of this traditional form of e-learning was mainly of generalizing the student's 
background, understanding, motivation, and basic skills [1]-[3]. Thus, dynamic learning was introduced that aims at achieving learning goals by adapting and personalizing the needs of students and the availability of learning materials. The mechanism behind dynamic learning was providing services or learning material suitable for students' needs when using e-learning. Research in the field of dynamic learning has been carried out extensively for many years, but the main problem that continues to be investigated in the literature is related to the model that can be reused in various e-learning systems [3], [4]. The model in this context covering adaptation model, user model, and domain knowledge model [5], [6]. The main issue addressed in this paper is modelling the user, student or learner, in a dynamic learning environment according to the situation and background learning framework [7]-[9].

A common condition in dynamic learning is the activity and progress of the student that constantly change over time and place. Therefore, this paper set out to identify attributes of learning that derived from interaction among pedagogy, technology, and knowledge transfer with the actors involved (student). Modeling students in dynamic learning has a vital role in transforming student characteristics while using elearning in the form of 'user profile'. The user profiles will have similar attributes between e-learning users. However, they will have different values between students depending on the context of learning. Combining the values and the attributes of the student model will form a learner profile of e-learning users. In simple terms, the learner modeling process is shown in Figure 1. Through this mechanism, the learner profiles will contain information that represents the characteristics of students at a specific moment of time. In the actual application of dynamic learning, the value data from student can be provided directly by the user or automatically obtained by the system from the user's behavior [1], [10].

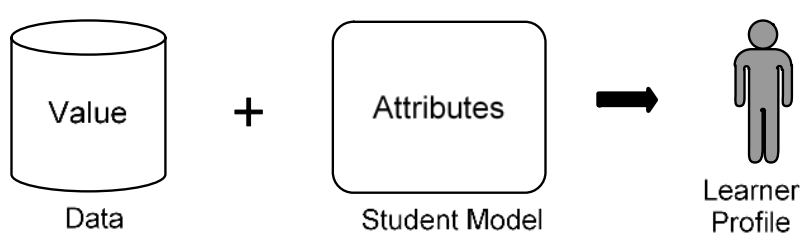

Figure 1. Learner model in e-learning

An early study of student modeling in e-learning was introduced by [11], that defines the following list of questions: "Who is being modeled?", "What is the characteristics of the student?", "How to model students?", and "Why student information is needed?". Furthermore, [11] succeeded in identifying student models in webbased adaptive learning systems that consist of user knowledge, interests, goals, background, individual characteristics, and context. The more comprehensive attributes of learner modeling were proposed in [12], [13] by considering human factors in determining the criteria. The attributes proposed include (1) personal user characteristics, such as name, age, gender, cognitive, personality, and learning style; (2) knowledge and skills, in the form of experience, knowledge, and psycho-motor skills; and (3) system-related user characteristics data, including objectives and requirements, preferences, interaction styles, and motivation. Several authors have also conducted similar research and contributed additional attributes of the learner model [14]-[16].

In fact, these many attributes have caused a new issue with the lack of attribute naming standards. Besides, the attributes that keep changing over time have often caused an impractical implementation of dynamic learning [2]. Considering the fact that e-learning continues to evolve and the environment is gradually changing, this study aims to make a classification of student modeling for dynamic learning. Specifically, this paper contributes to the literature in two ways. First, we propose the definitions of individual attributes of the learner model with reference to the current literature (2010-2020). Second, we intend to clarify the differences in students' attributes that exist in the current literature for APLS.

\section{RESEARCH METHOD}

In order to understand the role of learner model attributes in APLS, some research questions were posed to address the review:

- What are the main attributes that have been proposed to model the individual learner profile?

- What are the strategies proposed in the existing literature to utilize the known attributes?

- What are the current challenges and limitations for well-known attributes in APLS?

The domain of the study is limited to the individual attributes in an adaptive and personalized learning system. The research questions above are not addressed the accuracy or performance comparison of 
the existing attributes. However, we discuss how the existing literature utilizes each attributes to solve the issues raised in APLS.

This study adopted the meta-modeling creation process [17] for designing the learner model. The method contains the process of modeling various models (meta-modeling) to standardize and reuse the available models. The improvement of the method used in this research includes adding model collection, eliminating the use of relationships between concepts, and adding validation at the last stage. Furthermore, the method used in this study consisted of six modeling stages is being as:

- Step 1. Identification source of knowledge and collects learner models

The first step of the modeling is identifying the source of knowledge and collects learner models. This step aims to find a similar model that already exists in the literature in the domain of dynamic learning. The sources of knowledge were limited to web of science and scopus database. The articles were searched by the following four phrases: (dynamic OR adapt* OR personal*); (e-learning OR hypermedia OR "web-based learning” OR "intelligent tutoring"); ("learner model" OR "student model" OR "user model"); and (evaluate* OR empiric* OR experiment*). Then, the articles were filtered from the year 2010-2020, using English, and only from journals. The example of the source collection from Scopus was illustrated in Figure 2. After manually reviewing the model by considering the popularity of the citation number, 56 articles were selected from both databases. These 56 models contain designs and concepts of learner models in dynamic, adaptive, and personalized learning environments.

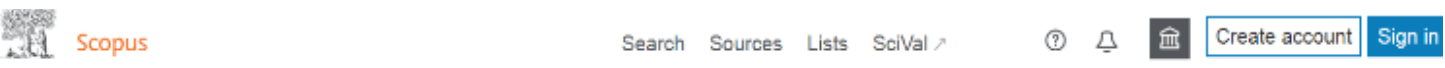

\section{1 document results}

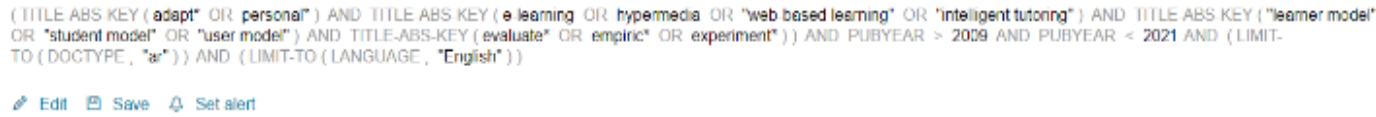

Figure 2. The article results from scopus database

- Step 2: Classification of the learner model

The aim of this step is to classify the learner model according to the defined criteria. In this paper, the criteria of the learner model in dynamic learning are the situation and background of the student [9]. The situation focuses on handling the condition when learning occurs, while the background focuses on defining the state of the study. These two classifications were selected since they represent a general taxonomy and not specific to a particular model. However, these classifications can be applied well to many models. The classification also worked well with dynamic learning by allowing direct mapping of the learner's attribute with a learning activity for adaptation purposes. From the 56 candidate models, 40 of them have been in accordance with the defined criteria, that is the completeness and coverage as suggested in [9]. Finally, the unused 16 models will be stored and used as comparisons in the final validation process.

- Step 3: Extraction of the concepts that relate to the learner model

The extraction process in this step is conducted by exploring the concepts (text mining) that have a high relationship with the learner model. The extracted concepts from the article must represent 'something' or 'object' from the students. For instance, "name, address, and gender" are the concept that might represent students. The example that illustrates the concept extraction process is shown in Table 1.

Table 1. Example of the extracted concepts from articles

\begin{tabular}{|c|c|c|c|}
\hline No. & Reference & Candidate Concepts & Total \\
\hline 1. & {$[18]$} & $\begin{array}{l}\text { Personal Data, Username, Country, Organization, Language, Performance Data, Time of Last } \\
\text { Session, Detail Level, Session Number, Programming Language, Teaching History, Concept } \\
\text { History, Test History, Unit History, Learning Style, Initial Skill Level, Experience Level, Actual } \\
\text { Skill Level, Duration, Number of Passes, Degree of Mastery, Knowledge Level, Instructional Plan, } \\
\text { Concept Title, Difficulty Factor }\end{array}$ & 25 \\
\hline 2. & [19] & $\begin{array}{l}\text { Experience, Background, Goals, Knowledge Level, Preference, Interest, Interaction Style, } \\
\text { Attitude, Learning Experience, Personality, Cognitive Style, Learning Performance, Time Taken, } \\
\text { Correct Answer, Trait }\end{array}$ & 15 \\
\hline 36. & [20] & $\begin{array}{l}\text { Personal Information, Contact, Demographic, Biographic, Qualification, Certification, } \\
\text { Performance, Preference, Format Presentation, Language, Media Type, Interest, Learning Goal, } \\
\text { Background Knowledge, Learning Style, Learning Activity, Prior Knowledge, Portfolio, Security, } \\
\text { Relation, Competency, Knowledge, Skill, Ability }\end{array}$ & 24 \\
\hline
\end{tabular}

Understanding the role of individual learner in adaptive and personalized ... (Alva Hendi Muhammad) 
- Step 4: Selection of the general concepts from the model

This step aims to improve the results of the concepts, as previously shown in Table 1 . The process includes selecting the most common (generality) and frequent concept names with more than three occurrence frequencies. For example, Table 2 shows the process of naming the concept. The word 'background' appears four times in various models, followed by 'background knowledge', and 'domain background'. Thus, the background will be selected as the name used as a general concept for background knowledge and background domain.

\begin{tabular}{llcc}
\multicolumn{1}{c}{ Table 2. Example of the naming process from selected models } \\
\hline General Concept & \multicolumn{1}{c}{ Concepts } & Frequency & Generality \\
\hline Background & Background & 4 & 1 \\
& Background Knowledge & 2 & 1 \\
& Background Domain & 1 & 0 \\
Cognitive Style & Cognitive & 1 & 1 \\
& Cognitive Ability & 1 & 1 \\
& Cognitive Capacity & 1 & 0 \\
& Cognitive Skills & 1 & 1 \\
& Cognitive Processing & 1 & 0 \\
Cognitive Purpose Indicator & 1 & 0 \\
& Cognitive State & 2 & 1 \\
& Cognitive Style & 4 & 1 \\
& Cognitive Task & 1 & 0 \\
& Level of Cognitive & 1 & 1 \\
& Visual and Cognitive & 1 & 0
\end{tabular}

- Step 5: Validation of the proposed concept

The validation aims to measure the concepts' quality and accuracy in terms of generalization, correctness, and completeness. Validation was conducted by comparing the frequency of occurrence of the data presented in Table 3 with the validation set suggested in the first step. Then, the degree of confidence (DoC) was measured. DoC value is a real number that expresses the reliability of the probability [17]. The formula of DoC is being as:

$$
\text { DoC }=\frac{\text { Frequency of Concept }}{\text { Total Model of VS } 1} \times 100 \%
$$

The final results of DoC and the proposed concept is presented in Table 3 . The validation in Table 4 aims to determine the final concept used as the learner model. The lower DoC value means the concept has a minor relationship with the suggested learner model. However, not all concepts in the very mild category are eliminated. Some concepts are still in use after comparing the occurrence rate with the 16 models from the validation set.

Table 3. Degree of confidence for the proposed concept

\begin{tabular}{ll}
\hline \multicolumn{1}{c}{ DoC Classification } & \multicolumn{1}{c}{ Learner Model Concepts } \\
\hline $70-100 \%$ (VeryStrong) & Knowledge Level, Prior Knowledge, Preference \\
$50-69 \%$ (Strong) & Learning Style, Background, Skills, Presentation, Time \\
$30-49 \%$ (Moderate) & Cognitive Style, Personality, Domain Concept, Learning Activity, Difficulty Level, Goal, Experience, \\
& Course, Interactivity \\
$11-29 \%$ (Mild) & Competency, Learning Performance, Device, Emotion, Interest, Learning Motivation, Objective \\
$0-10 \%$ (Very Mild) & Qualification, Instructional Plan, Bandwidth, Location, Age (x), Gender (x), Language (x), Personal \\
& Information $(\mathbf{x})$, Content $(\mathbf{x})$, Topic $(\mathbf{x})$ \\
\hline
\end{tabular}

$(\mathbf{x})=$ Delete the concept

Table 4. Final concept of the proposed learner model

\begin{tabular}{ll}
\hline \multicolumn{1}{c}{ Category } & \multicolumn{1}{c}{ Concepts } \\
\hline Situation & Bandwidth, Course, Device, Difficulty Level, Domain Concept, Emotion, Goal, Instructional Plan, Interactivity, \\
& Interest, Learning Activity, Learning Motivation, Location, Preference, Presentation, Time \\
Background & Background, Cognitive Style, Competency, Experience, Knowledge Level, Learning Style, Learning \\
& Performance, Objective, Personality, Prior Knowledge, Qualification, Skill
\end{tabular}




\section{RESULTS}

This section presents the findings of learner model attributes and then highlights the definition and specific data values for each attribute. The following sub-section then discuss the illustration of its value during the implementation. An example of using the learner model under a dynamic learning environment will also be presented.

The learning model suggested in this study follows the framework of situated learning as presented in [9]. We realize the adaptivity and personality in dynamic learning can be easily achieved by considering the situation and background of the learner simultaneously. Thus, the attributes of the learner should fall under these two categories: situation or background. The situation is any circumstances surrounding the student, while the background focuses on shaping the state of the learning history. The classification of the concept based on its categories is presented in Table 4. The lists of the concept were organized alphabetically. Even though some concepts might have a different degree of importance when implementing in the domain. However, to determine the degree of importance will need more information related to the implemented domain. Without understanding the implemented domain, it would be impractical to compare the importance of the concepts.

\subsection{Learning attributes related to situation}

Included in the category of situation is the concept that depends on the system. Therefore, this category encompasses all information related to the interaction between the user, system, device, infrastructure, and the environment. The description of each concept and example of the data instances based on literature are presented is being as:

- Bandwidth. Bandwidth provides information related to the network or internet connectivity in a specific amount of time. Some of the internet connectivity elements include: RFID, IrDA, Bluetooth, WiFi, WiMax, UMTS, 4G, or Satellite [1]. Moreover, bandwidth elements may include static and dynamic properties. The static properties may be a range of elements to represent the bandwidth values, such as low, medium, high, or defines as the minimum and maximum [13]; while the dynamic properties display the value of the actual speed or capacity of the network. Knowing the network connection gives insight into the e-learning system, to provide contents adaptation related to media presentation or size of resources that can be retrieved into student's device.

- Device. Device contains information related to the type of equipment that is used for learning. The information that is attached to a device contains technical elements, such as screen size, connectivity, central processing unit, interface, input/output, memory, and storage capacity, and battery lifetime. From these characteristics, we could refer to the hardware that the learner uses, such as PC, laptop, PDA, Smartphone, or Tablet [21]. The device information is important to determine the media presentation or learning resource that would be adaptable to the student [22].

- Difficulty Level. Difficulty level indicates the difference in the task that is hard to accomplish or understood by students. The difficulty level is relevant to determine the learners' abilities because inappropriate content can result in disorientation during learning. In particular, the dynamic parameter of difficulty level in different stages of learning to deliver appropriate learning content. In contrast, some studies used the static parameter to define the difficulty level. For instance, Ouf et al. [20] defined three values of high, fair, and low, as the difficulty parameter. Idris et al. [15] proposed a three-step difficulty level, which consists of Beginner, Intermediate, and Advanced. Another static parameter as suggested by [22] defined difficulty level by using the scale from 0 (easy) to 1 (difficult).

- Domain Concept. A domain concept consists of a topic of the domain. The domain concept can also be associated with learning objects in e-learning. The relationship among domain concepts of the course is known as the learning path. Information related to domain concepts is crucial for adaptation. This allows the system to generate and predict the content for the student based on the information in the domain concept. The information in the domain concept is also needed for determining the adaptation strategy, which is generally defined in the instructional model or adaptation model.

- Emotion. Emotion is described as a diffuse affective state that consists of a subjective feeling change without apparent cause. Different from mood, which tends to appear when things are not going well according to their expectation, emotion tends to come from a known cause [23]. For example, learners exhibit a happy emotion when they understand a topic or pass the test. Nevertheless, emotion is often combined and used interchangeably with mood to represent the affective states of the student [7].

- Goal. Goal is the description of an objective that the learner tries to achieve. The goal is simply the answer to the question: "What does the student want to achieve?" The goal can be modelled with possible learner goals or tasks that the system can recognize. Typically, a learner has to select one of the pre-defined goals. Cena et al. in [7], the goal's information is stored to indicate the particular topic in the system that the learner wants to visit. Some systems can capture goals from users and models as a probabilistic overlay [24]. Lamia and Tayeb [25] suggested two classifications of goal, that is the long-term goal and short-term 
goal. The long-term goal is the lifelong study plan and is typically permanent in the course. In contrast, the short-term goal provides the learner the opportunity to solve a certain problem, such as passing an assignment or doing a simulation. Goals can be modelled through navigation or monitoring dashboards. Learning goals are usually set at the beginning of the course, so that the system can provide information related to the goals that the learner wants to achieve. Then, the system might provide the needed resources to achieve the goals or remind the learners of their expected learning level.

- Instructional Plan. The instructional plan refers to a specific kind of strategy used to provide an effective learning object design to reach a more successful learning outcome. The instructional plan focuses on the current learning states, needs, and learning outcomes of students [18]. Also, the instructional plan is a developing functional learning system based on a systematic approach that meets the requirements of a specific target group.

- Interactivity. Interactivity level is described as the degree to which the student can influence the learning resource. Interactivity level promotes opportunities to interact with learning resources in different ways. Moreover, interactivity level indicates the degree to which the learning resource can respond to the actions and input of the user [26]. It has a value space range from very low to very high. The learning activity in very low interactivity level relates to passive activities with less response from the user, such as reading an essay or answering test questions [27]. Whereas the very high interactivity level value often relates to active response from the user, such as a 3D simulation environment that needs the user to do a series of steps.

- Interest. Interest is an indication of a learner being more attracted to a particular learning topic than others. This allows adaptive systems to make lessons that match the learner's interest. To represent user interest, some authors suggest the keywords-level model and concept-level model [28]. The keyword-level model uses a weighted vector of keywords to filter and retrieve the relevant learning materials to the keyword. In contrast to this approach, a concept-level model uses a weighted overlay of the concept-level domain model to represent user interests.

- Learning Activity. Learning activity is defined as any activity that the learner does while progressing through a unit of instruction in the course. Several types of learning activities exist according to cognitive or learning style. For instance, Felder-Silverman exemplifies learning activities like case studies, brainstorming, discussion, problem solving, experiments, observing, mind maps, group discussion, case studies, reading, storytelling, interviews, listening to lectures, questionnaires, and consulting references [20].

- Learning Motivation. Learning motivation is defined as the desire or the willingness to make an effort towards a specific learning goal. Learning motivation is often classified as a system-related characteristic because it intensely depends on the learning goal [29]. The learning goal itself is system-dependent and can be affected by the presentation of learning content [26].

- Location. Location is the representation of the place or position where the learner can be located. The location could be located automatically using position measurement from GPS or cellular ID [13]. However, most of them are usually selected manually by users according to the type of settings like a classroom, library, laboratory, home, outdoor, train, or bus [30]. Some works allow learners to create initial settings which consist of context attributes, such as location, time, and date [21].

- Preference. Preferences are the learning features that relate to likes and dislikes regarding interfaces, services, or resources. Preferences such as font type, size, and other parameters are associated with the interface [25]. The variables relate to device communication, hardware, and software which are associated with the service [29]. Furthermore, the preferred type of courses or instructional model can be associated with resources. Different methods have been proposed to gather learning preferences from the system. Ouf et al. [20] suggest using questionnaires for collecting learner preferences. This method provides real-time information without any need for further processing.

- Moreover, this method is similar to Lamia and Tayeb [25], which provides checklists for users to select preferred interface elements. After the preferences are determined, the system applies adaptation in the new contexts. The preference can also be defined as an ordered list of values, which indicate their likes and dislikes.

- Presentation. Presentation is described as the technical datatype or media type of the learning resource that is intended for presentation to the user. The information on the presentation can be used to identify the hardware and software needed to access the resources. The type of presentation may take several multimedia forms, such as text, picture, video, audio, application, animation, or hypertext [22].

- Time. In adaptive e-learning, time could represent the plan of activity, duration spent on studying, or indicate the date of learning [18]. Similar to location, time context is often used in conjunction with another context, either schedule, place, or motivation [7].

\subsection{Learning attributes related to background}

The background encompasses information regarding the general user, individual traits, experience, and learning history. Information related to the general user could be captured directly from the user's 
feedback. This mechanism differs from individual traits. Individual traits, including cognitive style, learning style, and personality, usually require separate testing and interpretation of the results. The description of the concept in this category are is being as:

- Background. In broad terms, background refers to the previous knowledge of a student in some particular areas, usually outside the domain of the concept but still relevant to the body of knowledge. For example, the background for students in the field of Computer Science or Information Technology might contain information related to knowledge in programming, system and development, networking, and operating systems [31]. The other fields will contain different information of the background [32].

- Cognitive Style. The cognitive style is often described as the way students think, observe, and remember information. Cognitive style, along with learning style, has become the essential concepts in adaptive learning. It encompasses the working memory, control and speed of processing, and visual attention [11], [33]. Researchers have identified that the cognitive processing of the human is often related to age, exercise, and experience [5], [16]. According to the wechsler adult intelligent scale (WAIS), the cognitive style could be classified into six broad types: information, comprehension, vocabulary, similarities, object assembly, and picture arrangement [34].

- Competency. Competency shows the qualification of a student in a field. Although this is not compulsory for the user model in dynamic learning, competency can be included as the learner's portfolio. Competency should represent that a student possesses the skills and knowledge required in a particular field [23]. A student with technologically related certification, for example, demonstrates the competency and knowledge that can be used to personalize content learning.

- Experience. Experience is the representation of the prior record associated with the learner's previous practice outside the core domain of the system. Some authors [6], [35] define experience as the user's general knowledge about a discipline. However, we also need to include the knowledge inside the discipline in the learning history. Thus, experience represents a range of backgrounds that might be used in modeling adaptive learning, including job, profession, responsibilities, or working experiences in related areas [6].

- Knowledge Level. Knowledge level represents an element record that reflects the expertise level of knowledge about a topic given. Knowledge level could represent the acquired knowledge or required knowledge. The acquired knowledge is the knowledge that the student acquires at a given level. This is also given to the student after they pass a chapter or a test. The required knowledge describes the necessary knowledge that students should have before studying a material. The knowledge level is essential in adaptive learning. A system can adapt the level of students and decide what the next stage of the learning process might be by accessing the knowledge of the learners. This way of adaptation is promoted by [15], [35], [36]. Knowledge level can also be reflected using performance level indicators, automatic system score, or question items level, such as well learned, learned, poor, and very poor [22].

- Learning Performance. Learning performance aims to measure the achievements and effectiveness of different kinds of learning activities. Learning performance can be determined by several methods. First is using learning goal or task accomplishment rates [37]. Second, the general measuring score of pre or post-test after completing a lesson. Then, academic performance by grading the result of pre and posttest. An effective assessment is a vital way to measure learners' performance and accomplishment of the learning outcomes. That is what learners are expected to know, understand, and do to be successful in a domain concept [38].

- Learning Style. Learning style is the way a student learns or prefers to learn. In fact, every student has different methods or strategies which they prefer when studying. Many studies have been done to investigate the specific learning style of students to improve the learning process. The selection of the appropriate learning style was derived from the educational and psychological fields. In e-learning environments, the common learning styles adopted for adaptive learning are Riding's Cognitive Style analysis [11], Felder/Silverman index of learning styles [39], [40], Myers-Briggs type indicator [41], and Kolb's model [42]. Some studies have proposed their own model as in [43], [44].

- Objective. The objective defines a classification of educational objectives that learners use to formulate their intentions. An objective in a subject can be measured by a degree of control that learners seek to achieve [45]. Many objectives of the study were derived from Bloom's taxonomy. According to Bloom's taxonomy, the objective of study can be classified into six categories: knowledge, understanding, application, analysis, synthesis, and evaluation.

- Personality. Personality reflects a record that stores the relevant learning attitude of a learner. According to Kim et al. [19], a learner's experience in e-learning will be affected significantly if the instruction style matches the learner's personality. That is why the modelling of personality is often closely tied to the preference for learning resource presentation. Some studies proposed different strategies of personality types, such as keirsey’s temperament theory (KTS), five-factor model, and MBTI [14], [41]. 
KTS suggests four personality types that are highly relevant to learning: Rational (intuitive thinking), Idealist (intuitive feeling), Artisan (sensory perception), and Guardian (sensory judgment). The fivefactor model also has different effects on learning. This personality consists of five dimensions: openness, conscientiousness, extraversion, agreeableness, and neuroticism. The MBTI model provides personality preferences along four bipolar psychological dimensions: introvert-extravert, sensingintuition, thinking-feeling, and judging-perceiving [46].

- Prior Knowledge. Prior knowledge is a way to represent the accumulation of knowledge and learning that each learner brings to a particular course. Prior knowledge aims to follow every student's activity during the learning process. It is a form of reflection of the student's performance or success/failure rate [40]. Prior knowledge data can be obtained from the result of the test, history of last visited learning resources, or time spent on completing a chapter [22], [35].

- Qualification. The qualification indicates the level of education of a learner. In IMS, education is used as a context to describe the environment where learning activities take places, such as University, School, Training, and others [7]. The qualification is used not only to represent the learning resources but also to represent the attributes of learners. Qualification can also be used to generate and personalize content that is matched with the education context [47].

- Skill. Skill represents the ability of a learner to perform well in a particular area. The skill of learner is often determined to personalize learning content based on the difficulty level. Skill might be used to represent a general ability in learning or just in a specific domain. For example, [18] uses skill to measure the degree of mastery in a specific programming language. The values range from bad (no skill) to expert (high skill). On the other hand, skill can also reflect the learner's general ability, such as mathematical skill, analytical, problem solving, reasoning, and logical thinking [47].

\section{DISCUSSION}

This sub-section analysis the difference of the findings with the existing learner models [3], [6]. A practical illustration of adaptation and personalization in dynamic learning will then be presented. We describe the application in mobile, ubiquitous, and pervasive learning [1], [48] and then show the proposed learner model identifying the context for adaptation.

\subsection{General framework for APLS}

The previous results have shown that a student might have many attributes in e-learning. Hence, an intelligence system is needed for processing learning materials based on learning context. To date, several intelligence learning tools and systems have been built with various modifications and improvements. The designs are generally similar to the framework shown in Figure 3 (adapted from [9]), which is divided into two domains. The first domain is context identification that handles the situation when learning occurs and defines the learner's state. The second domain is the adaptation and personalization process. It is the core of the system that will summarize the information and provide recommendations related to the available learning objects. Several methods currently exist for the assessment and recommendation of the learning object. The previous studies by [49], [50] provided an excellent review on this theme.

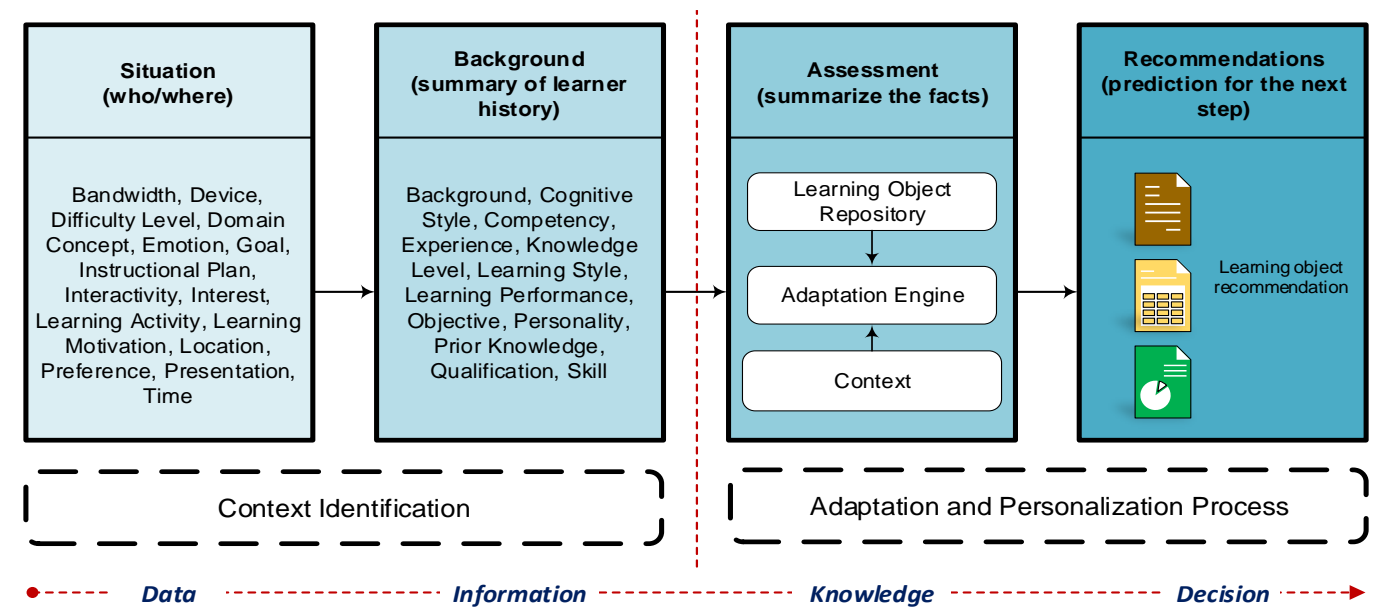

Figure 3. General APLS framework 


\subsection{Model comparison}

Comparison against other models can be used to identify the coverage of the concepts. First, we compare our model with the work of [3]. The source of literature in their model was from Science citation index expanded and social science citation index. Thus, the method for searching focuses on all individual characteristics, including learning styles, cognitive styles, background knowledge, age, and gender. The refinement was conducted by selection by titles, abstracts, and full texts. They also considered the citation number for each variable. Their final results successfully identified 17 attributes of the learner for adaptive learning, including age, gender, cognitive abilities such as processing speed, working memory, spatial ability, metacognitive abilities, personality, anxiety, emotional and affective states, cognitive styles, learning styles, experience, background knowledge, motivation, expectations, and preferences. The comparison with our model had shown that most of the suggested concepts supported, except age and gender. We already identified both concepts before, but they were dropped during validation since it less popular for adaptation in other models.

In addition, we compare our findings with the study of [6]. The study focused on identifying personal traits that can be identified for adaptive learning. The source of knowledge in the study was obtained from 78 sources related to personal traits, specifically in cognition, affective, behavior, or combination between domains. Their final results have identified the most factors suitable for adaptive learning, including learning style, cognitive style, emotions, cognitive abilities, knowledge level, and personality type. Since their research focuses on personal trait, our model's comparison was valid when comparing attributes in the background. Our model has identified all the suggested attributes for adaptive learning environments, from learning style to personality type.

\subsection{Model application}

In what follows, we illustrate our findings of the learner model for mobile, ubiquitous, and pervasive learning. Accordingly, the learner model determines the context during learning in two aspects: situation and background. Therefore, we first propose a set of values related to the situation. The data source of dimension could be identified directly by the system or manually supplied by the user. From the application description [1], the aim of the learning in this scenario is to assist the student during learning intermediate English. In this subject, student must individually and collaboratively present a project related to starting a new business. The context considered as the situation in the presented scenario is digital property, physical property, location, environment, availability, illumination level, and noise level. In addition, the scenario also considers the student's background, namely interest, need, preference, and contribution. Using our learner model, we identify the situation each student provided to the system is being as:

- Digital property and physical property are the software and hardware technical capabilities. These can be represented as device, bandwidth, and presentation.

- Location and environment are the descriptions of where the learners stand. Our model uses the similar name, i.e., location.

- Availability is the available time for learning. This can be represented as time.

- Illumination level and noise level where the learner is located. We identified this as interactivity.

Furthermore, the example of the background used by each student in this scenario are:

- Interest and contribution relate to learner's attention and interaction on learning skills to improve. This can be represented as interest, learning activity, goal, and objective.

- Need is a request for language support. This can be represented as difficulty level, knowledge level, and instructional plan.

- Preference is the inclination to select a service. We use a similar concept name to define preference.

Finally, the data context instantiated from learners is assessed to allow learning material recommendation. The recommendation is selected from the list of resources. These resources might in the form of learning activities, learning materials, learning objects, or services. In the scenario supported above, the resources are various learning activities that students should complete.

\section{CONCLUSION}

This paper has explored the different dimensions of learner modeling in dynamic learning, including transforming mechanisms to adapt and personalize learning. The impact of adaptive and personalized learning in formal education should be viewed as an opportunity to improve the learning experience. The process of producing a learner model included synthesizing a new learner model from existing models and validating the proposed model with several models in the existing domain. The result of the synthesis process is a generic learner model for the APLS. We also provided classification and dimension based on an assessment of the situation and background model. Focusing more on the proposed model, we presented all 
definitions and related data values for each proposed attribute. With the addition of the definition and data values, it is expected that this learner model would assist the researcher in reusing our model for implementing dynamic learning. Furthermore, we demonstrated the implementation of the learner model by assisting dynamic learning in mobile and ubiquitous contexts. This is an important contribution in developing a learner model that supports a dynamic learning environment and facilitating adaptation and personalization.

\section{REFERENCES}

[1] S. Gómez, P. Zervas, D. G. Sampson and R. Fabregat, "Context-aware adaptive and personalized mobile learning delivery supported by UoLmP," Journal of King Saud University (Computer and Information Sciences), vol. 26, no. 1, Supplement, pp. 47-61, 2014, doi: 10.1016/j.jksuci.2013.10.008.

[2] H. Xie, H. C. Chu, G. J. Hwang and C. C. Wang, "Trends and development in technology-enhanced adaptive/personalized learning: A systematic review of journal publications from 2007 to 2017," Computers \& Education, vol. 140, p. 103599, 2019, doi: 10.1016/j.compedu.2019.103599.

[3] J. Nakic, A. Granic and V. Glavinic, "Anatomy of student models in adaptive learning systems: A systematic literature review of individual differences from 2001 to 2013," Journal of Educational Computing Research, vol. 51, no. 4, pp. 459-489, January 2015, doi: 10.2190/EC.51.4.e.

[4] S. Y. Chen and J. H. Wang, "Individual differences and personalized learning: a review and appraisal," Universal Access in the Information Society, no. 0123456789, pp. 1-17, 2020, doi: 10.1007/s10209-020-00753-4.

[5] H. Yago, J. Clemente and D. Rodriguez, "Competence-based recommender systems: a systematic literature review," Behaviour \& Information Technology, vol. 37, no. 10-11, pp. 958-977, 2018, doi: 10.1080/0144929X.2018.1496276.

[6] N. B. A. Normadhi, L. Shuib, H. N. Md Nasir, A. Bimba, N. Idris and V. Balakrishnan, "Identification of personal traits in adaptive learning environment: Systematic literature review," Computers \& Education, vol. 130, pp. 168190, 2019, doi: 10.1016/j.compedu.2018.11.005.

[7] F. Cena, S. Likavec and A. Rapp, "Real World User Model: Evolution of User Modeling Triggered by Advances in Wearable and Ubiquitous Computing: State of the Art and Future Directions," Information Systems Frontiers, vol. 21, no. 5, pp. 1085-1110, 2019, doi: 10.1007/s10796-017-9818-3.

[8] S. S. Khanal, P. W. C. Prasad, A. Alsadoon and A. Maag, "A systematic review: machine learning based recommendation systems for E-learning," Education and Information Technologies, vol. 25, no. 4, pp. 2635-2664, 2020, doi: 10.1007/s10639-019-10063-9.

[9] A. Muhammad, J. Shen, G. Beydoun and D. Xu, "SBAR: A Framework to Support Learning Path Adaptation in Mobile Learning BT-Frontier Computing," in International Conference on Frontier Computing, vol. 422, pp. 655665, 2018, doi: 10.1007/978-981-10-3187-8_62.

[10] Y. M. Huang and P. S. Chiu, "The effectiveness of a meaningful learning-based evaluation model for contextaware mobile learning," British Journal of Educational Technology, vol. 46, no. 2, pp. 437-447, 2015, doi: $10.1111 /$ bjet.12147.

[11] P. Germanakos and M. Belk, "User Modeling," Human-Centred Web Adaptation and Personalization. Springer, Cham, pp. 79-102, 2016, doi: 10.1007/978-3-319-28050-9_3.

[12] L. A. Cárdenas-Robledo and A. Peña-Ayala, "A holistic self-regulated learning model: A proposal and application in ubiquitous-learning," Expert Systems with Applications, vol. 123, pp. 299-314, 2019, doi: 10.1016/j.eswa.2019.01.007.

[13] L. A. Cárdenas-Robledo and A. Peña-Ayala, "Ubiquitous learning: A systematic review," Telematics and Informatics, vol. 35, no. 5, pp. 1097-1132, 2018, doi: 10.1016/j.tele.2018.01.009.

[14] V. Slavuj, A. Meštrović and B. Kovačić, "Adaptivity in educational systems for language learning: a review," Computer Assisted Language Learning, vol. 30, no. 1-2, pp. 64-90, 2017, doi: 10.1080/09588221.2016.1242502.

[15] N. Idris, S. Z. M. Hashim, R. Samsudin and N. B. H. Ahmad, "Intelligent learning model based on significant weight of domain knowledge concept for adaptive E-learning," International Journal on Advanced Science, Engineering and Information Technology (IJASEIT), vol. 7, no. 4-2, pp. 1486-1491, 2017, doi: 10.18517/ijaseit.7.42.3408 .

[16] E. Mousavinasab, N. Zarifsanaiey, S. R. N. Kalhori, M. Rakhshan, L. Keikha and M. G. Saeedi, "Intelligent tutoring systems: a systematic review of characteristics, applications and evaluation methods," Interactive Learning Environments, vol. 29, no. 1, pp. 142-163, 2021, doi: 10.1080/10494820.2018.1558257.

[17] A. Al-Dhaqm, S. Razak, S. H. Othman, A. Ngadi, M. N. Ahmed and A. A. Mohammed, "Development and validation of a database forensic metamodel (DBFM)," PloS one, vol. 12, no. 2, p. e0170793, February 2017, doi: 10.1371/journal.pone.0170793.

[18] Z. Jeremić, J. Jovanović and D. Gašević, "Student modeling and assessment in intelligent tutoring of software patterns," Expert Systems with Applications, vol. 39, no. 1, pp. 210-222, January 2012, doi: 10.1016/j.eswa.2011.07.010.

[19] J. Kim, A. Lee and H. Ryu, "Personality and its effects on learning performance: Design guidelines for an adaptive E-learning system based on a user model," International Journal of Industrial Ergonomics, vol. 43, no. 5, pp. 450461, 2013, doi: 10.1016/j.ergon.2013.03.001.

[20] S. Ouf, M. Abd Ellatif, S. E. Salama and Y. Helmy, "A proposed paradigm for smart learning environment based on semantic web," Computers in Human Behavior, vol. 72, pp. 796-818, 2017, doi: 10.1016/j.chb.2016.08.030. 
[21] I. El Guabassi, Z. Bousalem, M. Al Achhab, I. Jellouli and B. E. El Mohajir, "Personalized adaptive content system for context-Aware ubiquitous learning," Procedia Computer Science, vol. 127, pp. 444-453, 2018, doi: 10.1016/j.procs.2018.01.142

[22] B. Dogan and E. Dikbıyık, "OPCOMITS: Developing an adaptive and intelligent web based educational system based on concept map model," Computer Applications in Engineering Education, vol. 24, no. 5, pp. 676-691, 2016, doi: 10.1002/cae.21740.

[23] N. Valle, P. Antonenko, D. Valle, K. Dawson, A. C. Huggins-Manley and B. Baiser, "The influence of task-value scaffolding in a predictive learning analytics dashboard on learners' statistics anxiety, motivation, and performance," Computers \& Education, vol. 173, p. 104288, 2021, doi: 10.1016/j.compedu.2021.104288.

[24] S. Sosnovsky and P. Brusilovsky, "Evaluation of topic-based adaptation and student modeling in QuizGuide," User Modeling and User-Adapted Interaction, vol. 25, no. 4, pp. 371-424, 2015, doi: 10.1007/s11257-015-9164-4.

[25] M. Lamia and L. M. Tayeb, "Discovering learner styles in adaptive E-learning hypermedia systems," Journal of Universal Computer Science, vol. 19, no. 11, pp. 1522-1542, 2013, doi: 10.3217/jucs-019-11-1522.

[26] A. Pensabe-Rodriguez, E. Lopez-Dominguez, Y. Hernandez-Velazquez, S. Dominguez-Isidro and J. De-la-Calleja, "Context-aware mobile learning system: Usability assessment based on a field study," Telematics and Informatics, vol. 48, p. 101346, 2020, doi: 10.1016/j.tele.2020.101346.

[27] S. V. Kolekar, R. M. Pai and M. P. M. M., "Rule based adaptive user interface for adaptive E-learning system," Education and Information Technologies, vol. 24, no. 1, pp. 613-641, 2019, doi: 10.1007/s10639-018-9788-1.

[28] P. Brusilovsky and E. Millán, "User models for adaptive hypermedia and adaptive educational systems," The adaptive web. Springer, Berlin, Heidelberg, vol. 4321 LNCS, pp. 3-53, 2007, doi: 10.1007/978-3-540-72079-9_1.

[29] C. Conati, O. Barral, V. Putnam and L. Rieger, "Toward personalized XAI: A case study in intelligent tutoring systems," Artificial Intelligence, vol. 298, p. 103503, 2021, doi: 10.1016/j.artint.2021.103503.

[30] H. Xie, D. Zou, R. Zhang, M. Wang and R. Kwan, "Personalized word learning for university students: a profilebased method for E-learning systems," Journal of Computing in Higher Education, vol. 31, no. 2, pp. 273-289, 2019, doi: 10.1007/s12528-019-09215-0.

[31] A. Peña-Ayala and L. Cárdenas, "A Revision of the Literature Concerned with Mobile, Ubiquitous and Pervasive Learning: A Survey," in Mobile, Ubiquitous, and Pervasive Learning: Fundaments, Applications, and Trends, Ed. Cham: Springer International Publishing, vol. 406, pp. 55-100, 2016, doi: 10.1007/978-3-319-26518-6 3.

[32] O. B. Yedri, L. El Aachak and M. Bouhorma, "Assessment-driven Learning through Serious Games: Guidance and Effective Outcomes," International Journal of Electrical and Computer Engineering (IJECE), vol. 8, no. 5, p. 3304, October 2018, doi: 10.11591/ijece.v8i5.pp3304-3316.

[33] S. Asai, D. T. D. Phuong, F. Harada and H. Shimakawa, "Predicting cognitive load in acquisition of programming abilities," International Journal of Electrical and Computer Engineering (IJECE), vol. 9, no. 4, pp. 3262-3271, August 2019, doi: 10.11591/ijece.v9i4.pp3262-3271.

[34] M. Lang, M. Matta, L. Parolin, C. Morrone and L. Pezzuti, "Cognitive profile of intellectually gifted adults: Analyzing the Wechsler Adult Intelligence Scale," Assessment, vol. 26, no. 5, pp. 929-943, 2019, doi: $10.1177 / 1073191117733547$.

[35] F. Colace, M. De Santo, D. Di Stasi and M. Casillo, "An adaptive educational hypermedia system for supporting students in their traditional learning process in computer engineering education," The International journal of engineering education, vol. 32, no. 4, pp. 1625-1636, 2016.

[36] A. E. Labib, J. H. Canós and M. C. Penadés, "On the way to learning style models integration: a Learner's Characteristics Ontology," Computers in Human Behavior, vol. 73, pp. 433-445, 2017, doi: 10.1016/j.chb.2017.03.054.

[37] S. Sarwar, Z. U. Qayyum, R. García-Castro, M. Safyan and R. F. Munir, "Ontology based E-learning framework: A personalized, adaptive and context aware model," Multimedia Tools and Applications, vol. 78, no. 24, pp. 3474534771, 2019, doi: 10.1007/s11042-019-08125-8.

[38] Y. Lin, S. Feng, F. Lin, W. Zeng, Y. Liu and P. Wu, "Adaptive course recommendation in MOOCs," KnowledgeBased Systems, vol. 224, p. 107085, 2021, doi: 10.1016/j.knosys.2021.107085.

[39] M. M. El-Bishouty et al., "Use of Felder and Silverman learning style model for online course design," Educational Technology Research and Development, vol. 67, no. 1, pp. 161-177, 2019, doi: 10.1007/s11423-018-9634-6.

[40] B. Arsovic and N. Stefanovic, "E-learning based on the adaptive learning model: case study in Serbia," SādhanāAcademia Proceeding Engineering Science, vol. 45, no. 1, pp. 1-13, 2020, doi: 10.1007/s12046-020-01499-8.

[41] M. Rastegarmoghadam and K. Ziarati, "Improved modeling of intelligent tutoring systems using ant colony optimization," Education and Information Technologies, vol. 22, no. 3, pp. 1067-1087, 2017, doi: 10.1007/s10639016-9472-2.

[42] J. Feldman, A. Monteserin and A. Amandi, "Automatic detection of learning styles: state of the art," Artificial Intelligence Review, vol. 44, no. 2, pp. 157-186, 2015, doi: 10.1007/s10462-014-9422-6.

[43] H. M. El-Bakry and A. A. Saleh, "Adaptive E-learning based on learner's styles," Bulletin Electrical Engineering and Informatics, vol. 2, no. 4, pp. 240-251, December 2013, doi: 10.11591/eei.v2i4.189.

[44] Ö. Özyurt and H. Özyurt, "Learning style based individualized adaptive E-learning environments: Content analysis of the articles published from 2005 to 2014," Computers in Human Behavior, vol. 52, pp. 349-358, 2015, doi: 10.1016/j.chb.2015.06.020.

[45] J. El Bouhdidi, M. Ghailani and A. Fennan, "A probabilistic approach for the generation of learning sessions tailored to the learning styles of learners," International Journal of Emerging Technologies in Learning (IJET), vol. 8, no. 6, pp. 42-49, 2013, doi: 10.3991/ijet.v8i6.3084.

[46] S. Fatahi, "An experimental study on an adaptive E-learning environment based on learner's personality and 
emotion," Education and Information Technologies, vol. 24, no. 4, pp. 2225-2241, 2019, doi: 10.1007/s10639-01909868-5.

[47] C. Romero and S. Ventura, "Educational data mining and learning analytics: An updated survey," WIREs Data Mining and Knowledge Discovery, vol. 10, no. 3, pp. 1-21, January 2020, doi: 10.1002/widm.1355.

[48] U. Lucke and C. Rensing, "A survey on pervasive education," Pervasive and Mobile Computing, vol. 14, pp. 3-16, 2014, doi: 10.1016/j.pmcj.2013.12.001.

[49] A. A. Kardan, M. Aziz and M. Shahpasand, "Adaptive systems: a content analysis on technical side for E-learning environments," Artificial intelligence review, vol. 44, no. 3, pp. 365-391, June 2015, doi: 10.1007/s10462-0159430-1.

[50] O. Zawacki-Richter, V. I. Marín, M. Bond and F. Gouverneur, "Systematic review of research on artificial intelligence applications in higher education - where are the educators?," International Journal of Educational Technology in Higher Education, vol. 16, no. 1, pp. 1-27, 2019, doi: 10.1186/s41239-019-0171-0.

\section{BIOGRAPHIES OF AUTHORS}

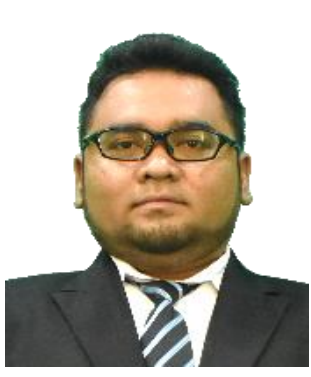

Alva Hendi Muhammad is a lecturer of Informatics Engineering at Universitas Amikom Yogyakarta in Indonesia. He also served as the Secretary of the Postgraduate Program in Informatics Engineering (distance learning). Alva has a Ph.D in IT from the University of Technology Sydney Australia. His research interests include AI for Engineering and Educational Technology, distance learning, as well as decision and expert system modeling.

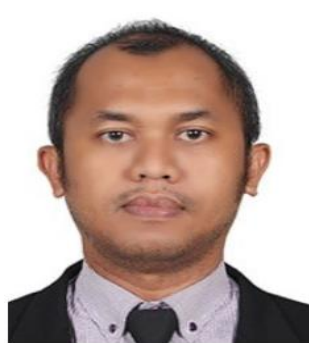

Dhani Ariatmanto is a full-time lecturer at the Faculty of Informatics, University of Amikom Yogyakarta. He was born in Jakarta, Indonesia, in 1980. Dhani received a master's degree in Informatics Engineering from the University of Amikom Yogyakarta. He is currently pursuing a doctoral program at Universiti Malaysia Pahang. His research interests include Image Processing, Digital Watermarking, and Multimedia Application. 